\title{
RNAi-Based Strategies for Cyclooxygenase-2 Inhibition in Cancer
}

\author{
Antonio Strillacci, Cristiana Griffoni, Maria Chiara Valerii, Giorgia Lazzarini, \\ Vittorio Tomasi, and Enzo Spisni
}

Department of Experimental Biology, University of Bologna, Via Selmi 3, 40126 Bologna, Italy

Correspondence should be addressed to Enzo Spisni, enzo.spisni@unibo.it

Received 12 October 2009; Revised 18 March 2010; Accepted 8 April 2010

Academic Editor: Chung-Liang Chien

Copyright (C 2010 Antonio Strillacci et al. This is an open access article distributed under the Creative Commons Attribution License, which permits unrestricted use, distribution, and reproduction in any medium, provided the original work is properly cited.

Cyclooxygenase-2 (COX-2) enzyme has been involved in the tumorigenesis and in the progression of colorectal cancer (CRC). The use of traditional nonsteroidal anti-inflammatory drugs (NSAIDs) or selective COX-2 inhibitors has been proposed for the prevention and the treatment of this relevant neoplastic disease. In the light of an innovative alternative to these pharmacological approaches, we review here the possible strategies to achieve a strong and selective inhibition of COX-2 enzyme by using the mechanism of RNA Interference (RNAi) targeted against its mRNA. Anti-COX-2 siRNA molecules (siCOX-2) can be generated in CRC cells from short hairpin RNA (shRNA) precursors, delivered in vitro by a retroviral expression system, and induce a significant and stable silencing of overexpressed COX-2 in human colon cancer cells. As a safer alternative to viral approach, nonpathogenic bacteria (E. coli) can be engineered to invade eukaryotic cells and to generate siCOX-2 molecules in cancer cells. Moreover, the involvement of miRNAs in COX-2 posttranscriptional regulation opens up the possibility to exploit an endogenous silencing mechanism to knockdown overexpressed COX-2. Thus, these recent strategies disclose new challenging perspectives for the development of clinically compatible siRNA or miRNA capable of selectively inhibiting COX-2 enzyme.

\section{Introduction}

1.1. COX-2 and Cancer. Several studies have supported the involvement of prostanoids in the pathogenesis of cancer. In vitro studies have demonstrated that growth factors, tumor promoters, and oncogenes induce prostanoids synthesis [1]. In vivo, the metabolism of arachidonic acid, via the COX pathway, has been found to be enhanced in various human tumors and it is now widely accepted that this is due to the induction of COX-2 enzyme [2]. A number of theories have been proposed to explain the role of tumor-derived prostanoids in promotion of angiogenesis, induction of tumor cell proliferation, suppression of immune response, and protection against apoptosis [3-5]. The expression of COX-1 and -2 in tumor tissues biopsies collected from various cancers has been analyzed. In particular, early studies by Eberhart et al. [6] and Sano et al. [7] showed that COX-2 is overexpressed in $80 \%$ of colorectal cancer tissues. In these transformed tissues, COX-2 enzyme results to be overexpressed in epithelial cells, inflammatory cells, as well as in stromal cells. In contrast, COX-2 expression is very low in adjacent normal tissues. COX-1 isoenzyme is expressed at the same basal level in both normal and tumor tissues. These findings have been confirmed analyzing many tumors including pancreas, skin, gastric, bladder, lung, head, and neck cancers [8], suggesting that COX-2, but not COX-1, may play a pivotal role in tumor formation and growth. More recent studies confirmed that the upregulated expression of COX-2, probably induced by carcinogenic stimuli or other tumor promoters, is an important contributor to tumorigenesis [9]. It is now clear that the tumorigenesis involves COX-2 overexpression in most cases, even if the molecular mechanisms responsible for this overexpression have not been completely understood. Different in vitro studies support the idea that COX-2 overexpression inhibits apoptosis and promotes tumor angiogenesis [2, 9, 10]. In fact, COX-2 overexpression in tissues seems to be crucial to favor the development of new vasculature supporting tumor growth and metastatization.

Following the development of animal models of tumorigenesis it has been demonstrated that NSAIDs strongly inhibit colon and breast tumors in rodents [11], further 
suggesting that products of the COX pathways may participate in carcinogen-induced tumorigenesis. The cancer chemopreventive activity of NSAIDs has been supported by epidemiological studies performed on humans taking aspirin and other NSAIDs on a regular basis. These studies demonstrate that incidence of various cancers, including colon, intestinal, gastric, breast, and bladder cancers, is reduced up to $40-50 \%$ [8]. Aspirin, which is a COX-1 and COX-2 inhibitor, has been shown to be moderately effective in preventing sporadic colorectal adenomas in patients with a familiar history of these tumors [12]. Epidemiological studies suggest that aspirin, especially if used in high doses for more than 10 years, is effective in reducing the incidence of colonic adenoma and CRC, even if careful consideration should be devoted to the possible harms of such a practice [13]. Celecoxib and rofecoxib, COX-2 selective drugs, have also been shown to reduce adenomas' incidence and to induce tumor regression in patients with familial polyposis $[14,15]$. Duodenal adenomas, which are otherwise untreatable, show some reduction by treatment with celecoxib [14]. The antineoplastic activity of NSAIDs has been extensively reviewed elsewhere [16]. Recent studies demonstrate that COX-2 blocking agents have strong potential for the chemoprevention of breast, prostate, colon, and lung cancers [17] and that multifactorial molecular events may be involved in such activity. Among them, the induction of apoptosis appears to be an essential factor in explaining the ability of these drugs to cause tumor regression [18]. Clinical trials have confirmed that NSAIDs, especially selective COX-2 inhibitors (coxibs), effectively prevent colorectal adenoma formation. On the basis of available data, COX-2 inhibitors are likely to be highly effective cancer chemopreventive agents. Yet, they also have substantial side-effects that currently limit their routine use [19]. The placebo-controlled trials APC (Adenoma Prevention with Celecoxib), PreSAP (Prevention of Spontaneous Adenomatous Polyps), and APPROVe (Adenomatous Polyp Prevention on Vioxx) of celecoxib and rofecoxib were stopped early because interim safety results indicated an increased cardiovascular risk in participants receiving active medication [20-22]. Since the COX-2 isoform is one of the major sources of endotheliumderived prostacyclin (PGI2) under physiological conditions, it has been hypothesized that selective blockade of COX-2 might impair endothelial function and predispose patients to cardiovascular disease $[23,24]$. Moreover, the cardiovascular toxicity of rofecoxib could be increased by its capability to directly inhibit prostacyclin synthase activity, as demonstrated by our group [25].

\section{COX-2 Silencing Mediated by siRNA}

In the last decade, RNA Interference (RNAi) has rapidly become an innovative and elective tool for studying genes function. Based on the works of Fire and Mello in 1998 on Caenorhabditis elegans [26], Hammond et al. and Zamore et al. in 2000 on Drosophila cells extracts [27, 28], and Tuschl and colleagues on mammalian cells [29], small interfering RNAs (siRNAs), 21-23 nt dsRNAs molecules with $2-3 \mathrm{nt}$ overhangs on their $3^{\prime}$-ends, were defined as the effectors of the RNAi pathway. They are capable of binding to homologous target mRNAs leading to cleavage of the transcript near the centre of the pairing sequence. To date, the RNAi pathway has been almost totally defined. Synthetic mature siRNAs can be transfected into cells or generated both in transient and stable manner from longer dsRNA precursors or from ssRNA molecules containing a complementary dsRNA domain called short hairpin RNAs (shRNAs). Active siRNAs are processed into cytoplasm by the RNase III endoribonuclease Dicer [30] and mRNA cleavage is mediated by a ribonucleoprotein complex, known as the RNA-induced silencing complex (RISC), after incorporation of the "guide" strand of the siRNA duplex. RISC contains one of the eight known Argonaute proteins in humans, Ago2, characterized by an RNA-binding domain (PAZ domain) and an RNase H-like domain (PIWI domain) [31].

RNAi technology has been successfully used to silence COX-2 protein in different in vitro models (Table 1). The use of innovative RNAi-based techniques has enabled researchers to better study the molecular and phenotypical loss of function of Cox-2 gene by performing experiments based on a strong COX-2 silencing deprived of aspecific effects. In 2003, Denkert and collaborators tested for the first time the efficacy of an anti-COX-2 siRNA (siCOX-2) on OVCAR-3 cells derived from human ovarian carcinoma [32]. A comparison with the COX-2 inhibitory drug NS-398 highlighted a different effect of siCOX-2 due to its highly specific mechanism of action. Even though COX-2 protein levels resulted significantly reduced in both cases after Il- $1 \beta$ stimulation, only NS-398 treatment induced a $\mathrm{G}_{0} / \mathrm{G}_{1}$ cell cycle arrest in OVCAR-3 cells. This effect could be due to the action of NS-398 on other cellular targets involved in cell proliferation, confirming the lack of specificity of NSAIDs in COX-2 blocking. Recent works by Charames and Bapat [33] and Kobayashi et al. [34] showed an efficient COX-2 knockdown mediated by siRNAs in HT-29 human colon cancer cells and bovine Cumulus-Granulosa (CG) cells, respectively. Based on their results on cell apoptosis [33], Charames and Bapat have confirmed a COX-2-independent mechanism of action of NSAIDs, previously described by several research groups [35-38]. From these studies, it results clear that RNAi, compared with NSAIDs, is a more powerful and selective tool for studying in vitro the functional role of COX-2.

However, RNAi-mediated COX-2 silencing proved to be highly effective using anti-COX-2 shRNAs (shCOX-2). In 2006, our group published a paper in which an in vitro strategy to stably knockdown COX-2 in colon cancer cells (HT29) was described [39]. Firstly, we tested different sequences of siCOX-2 in HUVE (human umbilical vein endothelial) cells. Among these, one siCOX-2 resulted to be more effective in silencing COX-2 protein after PMA transcriptional induction and led to a reduction of PGI2 levels and to the impairment of the ability of HUVE cells to organize capillary-like tubular structures in 3D gel. Furthermore, the active siCOX-2 sequence $\left(5^{\prime}\right.$-aactgctcaacaccggaattt- $\left.3^{\prime}\right)$ was used to design a shCOX-2 in order to silence COX2 in HT-29 colon cancer cells in a long-lasting manner. 
TABLE 1: COX-2 silencing mediated by RNAi.

\begin{tabular}{|c|c|c|c|c|}
\hline Study & Model & RNAi-silencing & Effects & Ref \\
\hline $\begin{array}{l}\text { Denkert et al. } \\
2003\end{array}$ & $\begin{array}{l}\text { OVCAR-3 cells } \\
\text { (human ovarian } \\
\text { carcinoma) }\end{array}$ & $\begin{array}{l}\text { siCOX-2 (short term } \\
\text { expression) }\end{array}$ & $\begin{array}{l}\text { - COX-2 protein silencing } \\
\text { - Reduction of } \mathrm{PGE}_{2} \text { levels } \\
\text { - No effects on cell proliferation }\end{array}$ & [32] \\
\hline $\begin{array}{l}\text { Strillacci et al. } \\
2006\end{array}$ & $\begin{array}{l}\text { HUVECs (human } \\
\text { umbilical vein } \\
\text { endothelial cells) }\end{array}$ & $\begin{array}{l}\text { siCOX-2 (short term } \\
\text { expression) }\end{array}$ & $\begin{array}{l}\text { - COX-2 protein silencing } \\
\text { - Reduction of 6-keto-PGF } \text { P }_{2 \alpha} \text { levels } \\
\text { - Reduction of capillary-like tubular } \\
\text { structures on 3D collagen gel } \\
\text { - No effects on interferon system }\end{array}$ & [39] \\
\hline $\begin{array}{l}\text { Strillacci et al. } \\
2006\end{array}$ & $\begin{array}{l}\text { HT- } 29 \text { cells (human } \\
\text { colon carcinoma) }\end{array}$ & $\begin{array}{l}\text { shCOX-2 (stable } \\
\text { expression) }\end{array}$ & $\begin{array}{l}\text { - COX-2 protein and mRNA silencing } \\
\text { - Reduction of } \mathrm{PGE}_{2} \text { levels } \\
\text { - No effects on interferon system } \\
\text { - No effects on cell proliferation } \\
\text { - Impairment of malignant behavior }\end{array}$ & [39] \\
\hline $\begin{array}{l}\text { Charames and } \\
\text { Bapat } 2006\end{array}$ & $\begin{array}{l}\text { HT- } 29 \text { cells (human } \\
\text { colon carcinoma) }\end{array}$ & $\begin{array}{l}\text { siCOX-2 (short term } \\
\text { expression) }\end{array}$ & $\begin{array}{l}\text { - COX-2 protein and mRNA silencing } \\
\text { - No effects on cell apoptosis }\end{array}$ & [33] \\
\hline $\begin{array}{l}\text { Kobayashi et al. } \\
2007\end{array}$ & $\begin{array}{l}\text { CG cells (bovine } \\
\text { Cumulus Granulosa) }\end{array}$ & $\begin{array}{l}\text { siCOX-2 (short-term } \\
\text { expression) }\end{array}$ & $\begin{array}{l}\text { - COX-2 mRNA silencing } \\
\text { - Reduction of } \mathrm{PGF}_{2 \alpha} \text { levels }\end{array}$ & [34] \\
\hline Wang et al. 2008 & $\begin{array}{l}\text { Hep-2 cells (human } \\
\text { laryngeal carcinoma) }\end{array}$ & $\begin{array}{l}\text { shCOX-2 (stable } \\
\text { expression) }\end{array}$ & $\begin{array}{l}\text { - COX-2 protein and mRNA silencing } \\
\text { - Inhibition of proliferation } \\
\text { - Impairment of malignant behavior } \\
\text { - Inhibition of in vivo growth } \\
\text { - Enhanced chemosensitivity in vitro and in vivo }\end{array}$ & {$[40]$} \\
\hline $\begin{array}{l}\text { Sansone et al. } \\
2008\end{array}$ & $\begin{array}{l}\text { HT- } 29 \text { cells (human } \\
\text { colon carcinoma) }\end{array}$ & $\begin{array}{l}\text { shCOX-2 (stable } \\
\text { expression) }\end{array}$ & $\begin{array}{l}\text { - COX-2 protein and mRNA silencing } \\
\text { - Inhibition of Erk phosphorilation } \\
\text { - Inhibition of CA-IX expression } \\
\text { - Inhibition of cell invasion } \\
\text { - Inhibition of MMP-2 activation } \\
\text { - No effects on cell death } \\
\text { - Inhibition of hypoxic survival }\end{array}$ & [41] \\
\hline
\end{tabular}

The stable expression of shCOX-2 in HT-29 (HT-29 $9^{\text {shCOX-2 }}$ ) induced a strong COX-2 silencing at protein, mRNA, and product (PGE2) levels, devoid of toxic effects (no activation of the interferon system). Phenotypically, COX-2 stable knockdown did not affect cell proliferation and cell cycle distribution but it strongly impaired the malignant behavior of HT-29 colon cancer cells in vitro. In fact, the invasiveness of HT-29 $9^{\text {shCOX-2 }}$ cells was reduced, as well as their ability to form colonies in soft-agar. This novel approach for COX2 silencing is very promising and its effectiveness has been further confirmed by the work of Wang and collaborators [40] who performed a stable silencing of COX-2 protein mediated by shRNA in human laryngeal carcinoma Hep-2 cells. In this model, COX-2 silencing induced a reduction of proliferation and invasiveness, coupled with increased apoptosis. Moreover, a reduced tumorigenesis was demonstrated with Hep- $2^{\text {shCOX-2 }}$ xenografts in nude mice. Finally, our HT$29^{\text {shCOX-2 }}$ model was successfully used to better elucidate the role of COX-2 in the hypoxic environment of colon cancer. In particular, we recently demonstrated an important interplay between COX-2 and carbonic anhydrase-IX (CA$\mathrm{IX}$, an enzyme controlling cellular $\mathrm{pH}$ ) that promotes the hypoxic survival and invasiveness of colon cancer cells [41].

\section{Transkingdom RNAi and Enhanced COX-2 Silencing}

Several years ago, it was demonstrated that systemic gene silencing occurs in the nematode Caenorhabditis elegans after ingestion of Escherichia coli engineered to produce interfering RNAs, thus suggesting that RNAi-mediated gene silencing between species or kingdoms might be possible $[42,43]$. Bacteria engineered to produce shRNAs can induce transkingdom RNAi (tkRNAi) in vitro and in vivo also in mammalian systems. A successful transfer of shRNAs into mammalian cells can be obtained using nonpathogenic $E$. coli transformed with a plasmid containing an expression 
cassette for shRNA and Inv/HlyA genes. In particular, Inv and HlyA encode the two bacterial factors (invasin and listeriolysin-O, resp.) responsible for the efficient transfer of shRNA from bacteria to mammalian cells. In 2006, Xiang et al. applied for the first time this new technology to silence $\beta-1$ catenin gene (CTNNB1) in human cells [44]. Firstly, they assessed the efficacy of tkRNAi against $\beta$-catenin in vitro on SW-480 colon carcinoma cell line. Then, $\beta$-catenin silencing tkRNAi-mediated was achieved also in vivo, in normal mouse intestinal epithelium and in xenografts of human colon cancer cells in mice. Based on these results, tkRNAi in mammals could represent a powerful and innovative strategy for functional genomics studies and for the development of clinically compatible RNAi-based therapies. In 2007, Cequent Pharmaceuticals (Cambridge, MA, USA) started to develop and validate new therapies for familial adenomatous polyposis (FAP) and CEQ501, the first tkRNAi-based drug, is currently in advanced preclinical trials [45].

In our laboratory, we have developed a tkRNAi-based strategy to efficaciously silence COX-2 in colon cancer cells. We tried to combine our knowledge on COX-2 knockdown mediated by RNAi with this transkingdom strategy (Figure 1). Infection of HCA-7 colon cancer cells with tkColi ${ }^{\text {shCOX-2 }}$ determined a significant reduction of COX2 mRNA and protein levels in this colon cancer cell lines (Figure 2). Moreover, COX-2 silencing mediated by tkRNAi induced a significant decrease in cell invasiveness in HT-29 and HCA-7 cell lines (Figure 2). We consider these data to be very promising and, as a consequence, we are trying to improve this strategy in order to obtain an enhanced and highly specific COX-2 silencing in colon cancer cells, in the light of compatible in vivo applications.

\section{Posttranscriptional Cox-2 Regulation Mediated by MicroRNAs}

MicroRNAs (miRNAs) have been found to be strongly implicated in the control of gene expression and it is believed that up to $30 \%$ of human genes are regulated by miRNAs [46]. To date, hundreds of miRNAs have been isolated in mammalians and their sequences are listed in the official miRNA database (miRBase, http://microrna.sanger.ac.uk/ index.shtml) [47]. Mature miRNA molecules (RNA duplexes of 19-24 nucleotides length with 2-nt overhangs in $3^{\prime}$-ends) are produced by the cellular machinery after the enzymatic cleavage of longer precursors (pri- and pre-miRNAs) [48, 49]. Following the incorporation into the RNA-induced silencing complex (RISC), the pairing of miRNAs (as singlestrand molecules) with target mRNAs carrying a partially complementary sequence in the $3^{\prime}$-untranslated region $\left(3^{\prime}\right.$ UTR) causes the translational repression and/or degradation of the messengers, resulting in the silencing of target genes [50].

miRNAs can regulate cellular genes involved in proliferation, in differentiation, or in apoptosis, and alterations of their expression have been found in various human tumors [51], including colon cancer [52]. In fact, data from recent literature clearly show that disturbances of miRNAs expression levels have detrimental effects on cell physiology and may be directly implicated in carcinogenic processes. These miRNAs, whose mutation or misexpression correlates with various human cancers, are defined "oncomiRs" and they can function as tumor suppressors or oncogenes [53]. Examples of oncomiRs are miRNAs from the miR-1792 family, miR-155 (overexpressed in chronic lymphocytic leukemia, CLL), miR-106a, miR-21, miR-221, miR-372, miR373 , and many others. MiR-15 and miR-16, let-7 family members, miR-143, and miR-145 have been defined tumor suppressor miRNAs since they are downregulated in some malignancies, including colon cancer $[54,55]$.

Many intracellular pathways contribute to the induction of COX-2 protein expression, both at transcriptional (see below) and post-transcriptional level. With regards to COX2 post-transcriptional regulation, it has been widely demonstrated that COX-2 mRNA shows an increased stability due to a mechanism that involves AU-rich regions in its $3^{\prime}$-UTR [56]. Moreover, novel data from literature have shown a direct link between COX-2 expression and miRNA-mediated translational silencing (Table 2). Dey and collaborators firstly described an inverse relationship between COX-2 and $\mathrm{miR}-101 \mathrm{a} / \mathrm{miR}-199 \mathrm{a}$ expression in mice. In particular, they have shown that low levels of miR-101a and miR199a associate with high COX-2 expression during mouse embryo implantation [57] and during mouse endometrial carcinogenesis [58]. Since COX-2 overexpression is involved in human CRC tumorigenesis, miR-101 and/or miR-199a could act as tumor suppressor miRNAs in CRC. This hypothesis has been confirmed in our laboratory. We recently reported the inverse correlation between COX2 and miR-101 expression in colon cancer cell lines and we demonstrated in vitro the direct inhibition of COX-2 mRNA translation mediated by miR-101. This correlation was supported also by data collected ex vivo, in which colon cancer tissues and liver metastases derived from CRC patients were analyzed [59]. These findings provide a novel molecular insight in the modulation of COX-2 at posttranscriptional level by miR-101 and strengthen the thesis that miRNAs are highly implicated in the control of gene expression. An impairment of miR-101 levels could represent one of the leading causes of COX-2 overexpression in colon cancer cells and, in our opinion, a novel CRC therapy could be based on COX-2 silencing mediated by miR-101 molecule.

Finally, it has been shown that also miR-16 plays a role in COX-2 mRNA destabilization and promotes its degradation in human THP-1 monocytic cells [60].

\section{Transcriptional-Based COX-2 Inhibition}

The control of Cox-2 gene transcription can be mediated by various transcription factors such as $\mathrm{NF}-\kappa \mathrm{B}[61], \mathrm{C} / \mathrm{EBP} \beta$ [62], CREB [63], NFAT [64], AP-1 [65], and PPAR [66], and it has been demostrated that also HIF- $1 \alpha$ factor induces COX-2 overexpression in hypoxic condition [67]. A transcriptional-based COX-2 inhibition could be developed by using selective inhibitors of these transcriptional factors. In particular, $\mathrm{C} / \mathrm{EBP} \beta$ seems to have a pivotal role in $\mathrm{COX}-2$ 


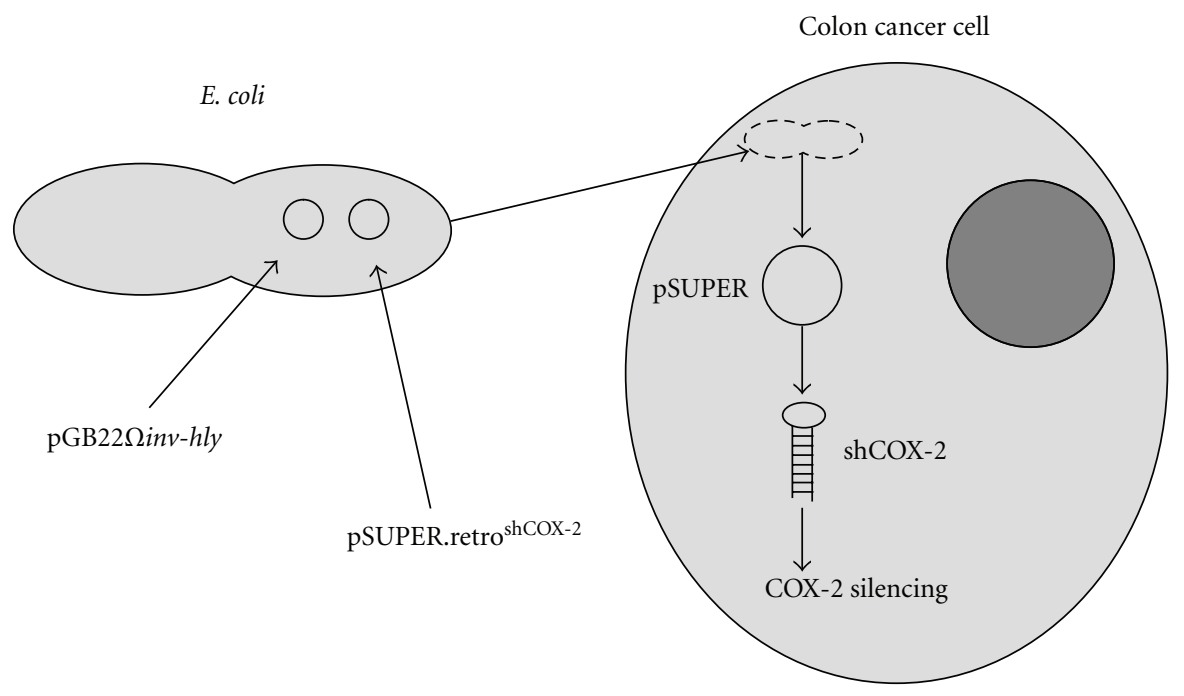

FIGURE 1: COX-2 silencing mediated by transkingdom RNAi. The cotransformation of E. coli with both plasmids pGB2Sinv-hly and pSUPER.retro ${ }^{\text {shCOX-2 }}$ enables bacteria to induce the transkingdom RNAi phenomenon in colon cancer cells. Following the expression of the bacterial proteins invasin and listeriolysin-O, engineered E. coli strains are able to permeate human cells and release the plasmid DNA content. Anti-COX-2 shRNAs are then transcribed by the cellular machinery, resulting in an efficient COX-2 silencing.

TABLE 2: Anti-COX-2 miRNAs.

\begin{tabular}{|c|c|c|c|c|}
\hline Study & miRNAs & Model & Function & Ref \\
\hline $\begin{array}{l}\text { Chakrabarty } \\
\text { et al. } 2007\end{array}$ & $\begin{array}{l}\text { mmu-miR 199a* } \\
\text { mmu-miR-101a }\end{array}$ & mouse & $\begin{array}{l}\text { - Correlate inversely with COX-2 protein } \\
\text { during embryo implantation } \\
\text { - Regulate COX-2 protein expression }\end{array}$ & [57] \\
\hline $\begin{array}{l}\text { Daikoku et al. } \\
2008\end{array}$ & $\begin{array}{l}\text { mmu-miR-199a* } \\
\text { mmu-miR-101a }\end{array}$ & mouse & $\begin{array}{l}\text { - Correlate inversely with COX-2 protein } \\
\text { in endometrial cancer cells }\end{array}$ & {$[58]$} \\
\hline $\begin{array}{l}\text { Strillacci et al. } \\
2008\end{array}$ & hsa-miR-101 & homo & $\begin{array}{l}\text { - Correlates inversely with COX-2 protein } \\
\text { in colon cancer cells } \\
\text { - Regulates COX-2 protein expression } \\
\text { (translational repression) }\end{array}$ & [59] \\
\hline $\begin{array}{l}\text { Shanmugam } \\
\text { et al. } 2008\end{array}$ & hsa-miR-16 & homo & $\begin{array}{l}\text { - Promotes COX-2 mRNA degradation in } \\
\text { THP-1 monocytic cells }\end{array}$ & {$[60]$} \\
\hline
\end{tabular}

transcriptional activation by proinflammatory mediators $[62,68,69]$ and in cancer cells $[70,71]$. Moreover, it has been demonstrated that salicylate at pharmacological concentration inhibits COX-2 expression (50\%) by blocking $\mathrm{C} / \mathrm{EBP} \beta$ phosphorylation and activation via p90 ribosomal S6 kinase 1/2 (RSK1/2) [72]. Based on these pieces of evidence, $\mathrm{Wu}$ and colleagues have proposed that the inhibition of RSK1/2 or C/EBP $\beta$ expression by specific siRNAs and/or the inhibition of RSK1/2 activity by pharmacological approaches may have therapeutic potential in reducing COX-2 overexpression in human pathologies (e.g., inflammation, cancer) without affecting the physiological function of COX-2 enzyme. However, transcriptional-based COX-2 inhibition could lack specificity since transcriptional factors are involved in the control of a wide number of genes and RSK1/2 is involved in phosphorylation of other proteins that may have a role in cell physiology [73].

\section{Conclusion}

Considering the recent literature regarding the application of RNAi-based strategies to modulate gene expression and the study of miRNAs-mediated COX-2 silencing, new COX2 selective inhibitors based on siRNA or miRNA molecules could be developed. In particular, we suggest that anti-COX2 siRNAs (siCOX-2) and/or miRNAs (miR-101, miR-199a) may represent innovative tools for COX-2 silencing, especially in CRC therapy. To date, selective COX-2 inhibitors (coxibs) have been tested for CRC treatment but, despite the efficacy in COX-2 blockade, an increased cardiovascular risk has been observed in chronically treated patients. In order to prevent adverse side-effects, tissue-specific expression, and targeting of siCOX-2, miR-101 or miR-199a could lead to a strong and highly specific COX-2 silencing deprived of secondary effects on other targets (e.g., PGI2 synthase) or other tissues (e.g., cardiovascular system). 


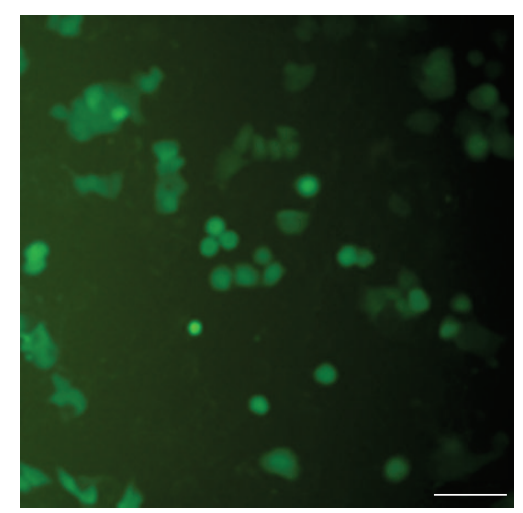

HT-29

(a)

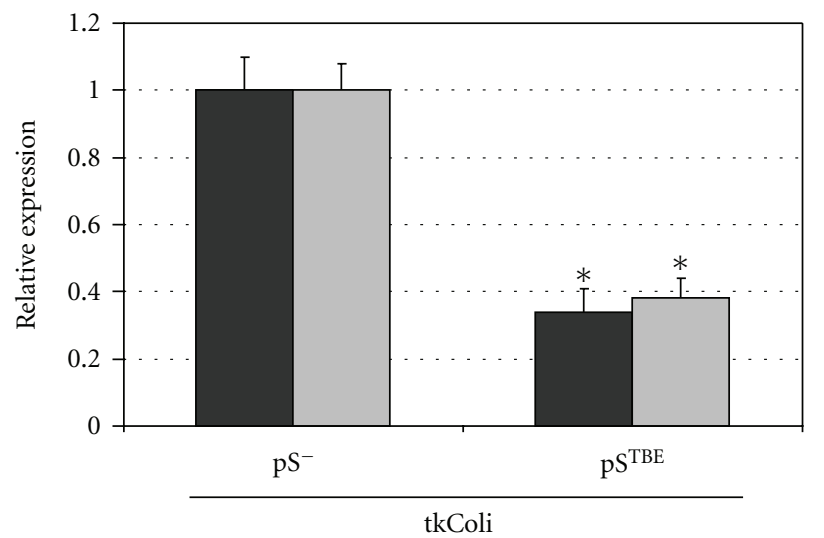

COX-2 mRNA

COX-2 protein

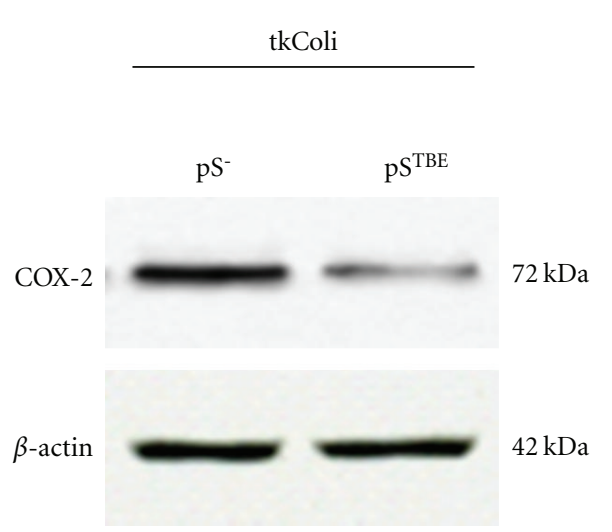

(b)

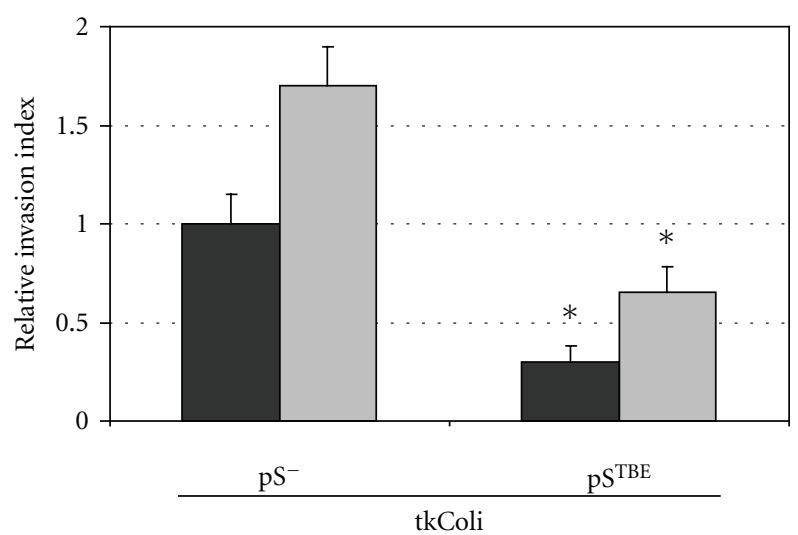

PMA -

PMA +

(c)

(d)

FIGURE 2: Invasive tkColi infect CRC HT-29 cells and promote high COX-2 silencing associated with a reduced invasive behavior. E. coli was cotransformed with pGB2- $\Omega$-inv-hly plasmid and pSUPER.retro vectors to obtain $E$. coli invasive strains carrying the shCOX-2 expression vector tkColi-pSTBE (in which shCOX-2 expression is controlled by TBE promoter carrying Tcf Binding Elements). The negative control was tkColi-pS-(not expressing shCOX2 but containing the original empty pSUPER.retro vector). GFP protein expression (a) was used to evaluate the efficiency of tkColi infection of HT-29 cells (bar $=30 \mu \mathrm{m}$ ). 72 hours after the infection, the efficiency of infection was higher than $75 \%$. The expressions of COX-2 protein and COX-2 mRNA were analyzed in HT-29 cells, 72 hours after tkColi infection, by Western blot and realtime PCR (c). COX-2 protein and COX-2 mRNA expressions were normalized against $\beta$-actin protein and GUSB ( $\beta$-glucuronidase) mRNA levels, respectively. Relative expression of COX-2 protein and COX-2 mRNA refers to tkColi-pS-infected sample. The invasive behavior of tkColi infected CRC HT-29 cells was evaluated by using Boyden chambers and $8-\mu \mathrm{m}$ polycarbonate membranes coated with Matrigel. Samples were tested in the absence (dark bars) and in the presence (light bars) of PMA $40 \mathrm{nM}$. Relative invasion index refers to HT-29 cells infected with tkColi-pS-, not treated with PMA. Data reported in (b)-(d) represent the mean \pm SEM of three independent experiments; ${ }^{*} P<.01$.

Many research groups and companies are trying to develop completely new strategies based on miRNAs for an in vivo therapeutic application. Even though miRNAs expression patterns in human cells are not completely understood, the possibility of their modulation represents an exciting challenge for targeting COX-2 activity in vivo. However, clinical trials based on therapeutic small RNAs are still far. The efficiency of siRNAs and miRNAs delivery into target cells, using a nonviral delivery system, is still inadequate. To overcome these barriers, a wide number of modified small RNAs and functional carriers have been developed as an alternative strategy to viral vectors which cannot be considered safe vehicles for therapeutic application in humans. In vivo, the efficacy of delivered siRNAs depends on different factors such as pharmacokinetics, resistance to exonuclease digestion, or maintenance of duplexes integrity. Locked nucleic acids (LNAs), siRNAs with a partial phosphorothioate backbone, or siRNAs with the inclusion of $2^{\prime}$-O-methyl dinucleotides at the $3^{\prime}$-end of the antisense strand have shown enhanced stability. Improvements on the pharmacodynamics of siRNAs were obtained as well, using conjugated-siRNAs (e.g., cholesterol-conjugated) [74] 


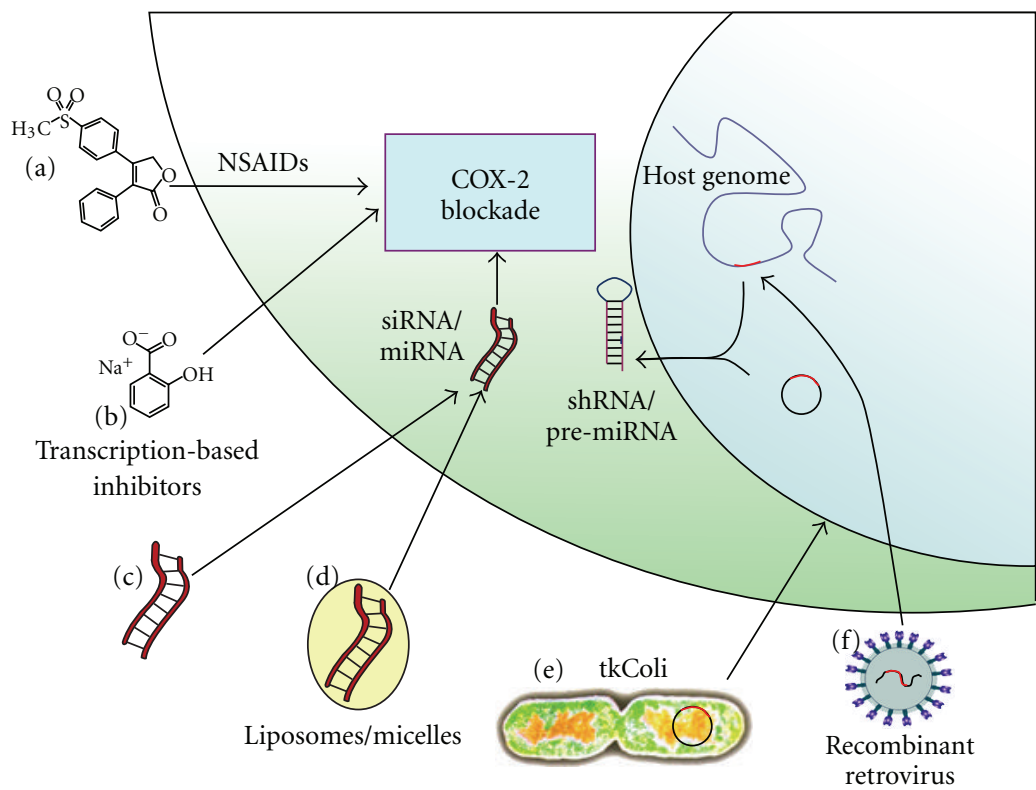

FIgURE 3: The different strategies for COX-2 blockade. (a) COX-2 selective NSAIDs (e.g., celecoxib, rofecoxib, etoricoxib) represent to date the only drugs marketed for COX-2 selective inhibition, even if rofecoxib has been withdrawn due to its toxicity; (b) inhibitors of transcriptional factors expression and/or activity (e.g., C/EBP $\beta$ transactivator) may block COX-2 overexpression associated to inflammation or cancer; (c) anti-COX-2 siRNAs (siCOX-2) or miRNAs (e.g., miR-101) with structural modifications that improve their stability may block COX-2 expression after intravenous administration; (d) polymer- or lipid-based delivery systems protect siRNAs or miRNA from the extracellular environment and, modifying their shell, a more selective cellular targeting can be obtained; (e) nonpathogenic bacteria (E. coli) can be engineered in order to invade target cells and induce RNAi against COX-2 (transkingdom RNAi, tkRNAi) by releasing DNA plasmids that express siCOX-2 or miR-101 precursors; (f) anti-COX-2 shRNA (shCOX-2) or pre-miRNA expression cassettes can be transduced into target cells genome by the use of recombinant retroviruses, allowing a stable COX-2 silencing into mammalian cells.

or protecting siRNAs from the extracellular environment with polymer- or lipid-based delivery systems (e.g., cationic polyethylenimines or lipid-polyethylene glycol mixtures) $[75,76]$. Cationic liposome-mediated delivery of anti-COX2 siRNA was recently used in vivo [77] and resulted in an efficient downregulation of COX-2 in tumor cells. Furthermore, various types of synthetic carrier systems for small RNAs delivery have been developed to target tumor tissues preferentially through the blood stream, such as polyplexes [78]. In our laboratories, biocompatible polymeric micelles have shown to be nontoxic carriers capable to efficiently deliver small RNA molecules into mammalian cells cytosol (Benaglia M. and Spisni E, Ms. Submitted). The possibility to modify their shell, in order to obtain a more selective cellular targeting, has been documented by many authors $[77,79]$, opening up the perspective to deliver in vivo small RNA molecules in a specific and efficient manner.

Nonpathogenic bacteria, engineered to induce tkRNAi against COX-2 in CRC cells (tkColi ${ }^{\text {shCOX-2 }}$ ), could represent an innovative and potent strategy to achieve a strong COX2 silencing directly in the intestinal mucosa of the patients affected by CRC, with a relatively high specificity associated with low systemic effects. Moreover, this approach directed against other cellular targets, such as tumor necrosis factor alpha ( TNF $\alpha$ ), could be also very promising for the treatment of other inflammatory bowel diseases (e.g., ulcerative colitis, Crohn's disease).
Important remarks could be made about the use of siRNAs instead of miRNAs for an anti-COX-2 therapeutic application. In general, both siRNAs and miRNAs can induce effective gene silencing by a similar mechanism of action [80] and the effective delivery of their mature molecules can be improved by using the same techniques. However, siRNAs and miRNAs have a different specificity in silencing genes and they can induce a different toxicity when transiently or constitutively expressed directly in mammalian cells. We cannot completely exclude that siCOX-2 could generate off-target effects in treated cells, silencing other mRNAs that have partial complementarity [81]. Similarily, COX-2 inhibition mediated by miR-101 or miR-199a could interfere with the expression of other target genes [82-85]. Surely, an miR-101/199a control of COX-2 expression could represent a more suitable approach for the treatment of human pathologies characterized by both COX-2 overexpression and miR-101 downregulation (e.g., colon cancer, endometrial serous adenocarcinoma) $[59,86]$. Even though an shRNA/siRNA-mediated gene silencing could result more effective [87], a constitutive expression of shRNAs could lead to a lower specificity of action and a higher level of toxicity. This may be due to the saturation of the cellular machinery deputed to endogenous miRNAs processing and exportation [88] causing the induction of nonsequencespecific silencing pathway (e.g., interferon system activation) which is not observed when using miRNAs [89, 90]. In 
the light of this evidence, it is likely that miRNA-based strategies for COX-2 inhibition may be a more appropriate alternative for the treatment of human pathologies associated to COX-2 overexpression. These different strategies for COX2 blockade are summarized in Figure 3.

Finally, since transactivators such as $\mathrm{C} / \mathrm{EBP} \beta$ are strongly implicated in COX-2 induction at transcriptional level, we suggest that inhibition of $\mathrm{C} / \mathrm{EBP} \beta$ expression or activity by the use of RNAi or other molecular compounds may reduce COX-2 overexpression associated to human pathologies such as inflammation or colon cancer.

\section{Acknowledgments}

The present work was supported by grants from MIUR (FIRB 2003 RBNE03FMCJ to V. Tomasi and PRIN 2008MT34AP to E. Spisni). The authors also thank Dr. Catherine GrillotCourvalin (Unité des Agents Antibactériens, Institut Pasteur, Paris) for providing them $p G B 2-\Omega$-inv-hly plasmid. A. Strillacci and C. Griffoni contributed equally to this work.

\section{References}

[1] L. Levine, "Arachidonic acid transformation and tumor production," Advances in Cancer Research, vol. 35, pp. 49-79, 1981.

[2] R. N. DuBois, S. B. Abramson, L. Crofford, et al., "Cyclooxygenase in biology and disease," FASEB Journal, vol. 12, no. 12, pp. 1063-1073, 1998.

[3] D. Wang and R. N. DuBois, "Prostaglandins and cancer," Gut, vol. 55, no. 1, pp. 115-122, 2006.

[4] M. A. Iniguez, A. Rodriguez, O. V. Volpert, M. Fresno, and J. M. Redondo, "Cyclooxygenase-2: a therapeutic target in angiogenesis," Trends in Molecular Medicine, vol. 9, no. 2, pp. 73-78, 2003.

[5] A. Greenhough, H. J. M. Smartt, A. E. Moore, et al., "The COX-2/PGE2 pathway: key roles in the hallmarks of cancer and adaptation to the tumour microenvironment," Carcinogenesis, vol. 30, no. 3, pp. 377-386, 2009.

[6] C. E. Eberhart, R. J. Coffey, A. Radhika, F. M. Giardiello, S. Ferrenbach, and R. N. DuBois, "Up-regulation of cyclooxygenase 2 gene expression in human colorectal adenomas and adenocarcinomas," Gastroenterology, vol. 107, no. 4, pp. 11831188, 1994.

[7] H. Sano, Y. Kawahito, R. L. Wilder, et al., "Expression of cyclooxygenase-1 and -2 in human colorectal cancer," Cancer Research, vol. 55, no. 17, pp. 3785-3789, 1995.

[8] M. J. Thun, S. J. Henley, and C. Patrono, "Nonsteroidal anti-inflammatory drugs as anticancer agents: mechanistic, pharmacologic, and clinical issues," Journal of the National Cancer Institute, vol. 94, no. 4, pp. 252-266, 2002.

[9] C. H. Liu, S.-H. Chang, K. Narko, et al., "Overexpression of cyclooxygenase-2 is sufficient to induce tumorigenesis in transgenic mice," Journal of Biological Chemistry, vol. 276, no. 21, pp. 18563-18569, 2001.

[10] M. Tsujii, S. Kawano, S. Tsuji, H. Sawaoka, M. Hori, and R. N. DuBois, "Cyclooxygenase regulates angiogenesis induced by colon cancer cells," Cell, vol. 93, no. 5, pp. 705-716, 1998.

[11] R. S. Reddy, H. Maruyama, and G. Kelloff, "Dose-related inhibition of colon carcinogenesis by dietary piroxicam, a nonsteroidal antiinflammatory drug, during different stages of rat colon tumor development," Cancer Research, vol. 47, no. 20, pp. 5340-5346, 1987.

[12] R. S. Sandler, S. Halabi, J. A. Baron, et al., "A randomized trial of aspirin to prevent colorectal adenomas in patients with previous colorectal cancer," The New England Journal of Medicine, vol. 348, no. 10, pp. 883-890, 2003.

[13] C. Dubé, A. Rostom, G. Lewin, et al., "The use of aspirin for primary prevention of colorectal cancer: a systematic review prepared for the U.S. Preventive Services Task Force," Annals of Internal Medicine, vol. 146, pp. 365-375, 2007.

[14] R. K. S. Phillips, M. H. Wallace, P. M. Lynch, et al., "A randomised, double blind, placebo controlled study of celecoxib, a selective cyclooxygenase 2 inhibitor, on duodenal polyposis familial adenomatous polyposis," Gut, vol. 50, no. 6, pp. 857-860, 2002.

[15] T. Higuchi, T. Iwama, K. Yoshinaga, M. Toyooka, M. M. Taketo, and K. Sugihara, "A randomized, double-blind, placebo-controlled trial of the effects of rofecoxib, a selective cyclooxygenase-2 inhibitor, on rectal polyps in familial adenomatous polyposis patients," Clinical Cancer Research, vol. 9, no. 13, pp. 4756-4760, 2003.

[16] W. Dempke, C. Rie, A. Grothey, and H.-J. Schmoll, "Cyclooxygenase-2: a novel target for cancer chemotherapy," Journal of Cancer Research and Clinical Oncology, vol. 127, no. 7, pp. 411-417, 2001.

[17] R. E. Harris, J. Beebe-Donk, and G. A. Alshafie, "Cancer chemoprevention by cyclooxygenase 2 (COX-2) blockade: results of case control studies," Sub-Cellular Biochemistry, vol. 42, pp. 193-212, 2007.

[18] N. R. Jana, "NSAIDs and apoptosis," Cellular and Molecular Life Sciences, vol. 65, no. 9, pp. 1295-1301, 2008.

[19] M. M. Bertagnolli, "Chemoprevention of colorectal cancer with cyclooxygenase-2 inhibitors: two steps forward, one step back," Lancet Oncology, vol. 8, no. 5, pp. 439-443, 2007.

[20] S. D. Solomon, J. J. V. McMurray, M. A. Pfeffer, et al., "Cardiovascular risk associated with celecoxib in a clinical trial for colorectal adenoma prevention," The New England Journal of Medicine, vol. 352, no. 11, pp. 1071-1080, 2005.

[21] B. M. Psaty and J. D. Potter, "Risks and benefits of celecoxib to prevent recurrent adenomas," The New England Journal of Medicine, vol. 355, no. 9, pp. 950-952, 2006.

[22] R. S. Bresalier, R. S. Sandler, H. Quan, et al., "Cardiovascular events associated with rofecoxib in a colorectal adenoma chemoprevention trial," The New England Journal of Medicine, vol. 352, no. 11, pp. 1092-1102, 2005.

[23] M. R. Weir, R. S. Sperling, A. Reicin, and B. J. Gertz, "Selective COX-2 inhibition and cardiovascular effects: a review of the rofecoxib development program," American Heart Journal, vol. 146, no. 4, pp. 591-604, 2003.

[24] G. A. FitzGerald, "Coxibs and cardiovascular disease," The New England Journal of Medicine, vol. 351, no. 17, pp. 17091711, 2004.

[25] C. Griffoni, E. Spisni, A. Strillacci, M. Toni, M. M. Bachschmid, and V. Tomasi, "Selective inhibition of prostacyclin synthase activity by rofecoxib," Journal of Cellular and Molecular Medicine, vol. 11, no. 2, pp. 327-338, 2007.

[26] A. Fire, S. Xu, M. K. Montgomery, S. A. Kostas, S. E. Driver, and C. C. Mello, "Potent and specific genetic interference by double-stranded RNA in caenorhabditis elegans," Nature, vol. 391, no. 6669, pp. 806-811, 1998.

[27] S. M. Hammond, E. Bernstein, D. Beach, and G. J. Hannon, "An RNA-directed nuclease mediates post-transcriptional gene silencing in Drosophila cells," Nature, vol. 404, no. 6775, pp. 293-296, 2000. 
[28] P. D. Zamore, T. Tuschl, P. A. Sharp, and D. P. Bartel, "RNAi: double-stranded RNA directs the ATP-dependent cleavage of mRNA at 21 to 23 nucleotide intervals," Cell, vol. 101, no. 1, pp. 25-33, 2000.

[29] S. M. Elbashir, J. Harborth, W. Lendeckel, A. Yalcin, K. Weber, and T. Tuschl, "Duplexes of 21-nucleotide RNAs mediate RNA interference in cultured mammalian cells," Nature, vol. 411, no. 6836, pp. 494-498, 2001.

[30] E. Bernstein, A. A. Caudy, S. M. Hammond, and G. J. Hannon, "Role for a bidentate ribonuclease in the initiation step of RNA interference," Nature, vol. 409, no. 6818, pp. 363-366, 2001.

[31] J. Liu, M. A. Carmell, F. V. Rivas, et al., "Argonaute2 is the catalytic engine of mammalian RNAi," Science, vol. 305, no. 5689, pp. 1437-1441, 2004.

[32] C. Denkert, A. Fürstenberg, P. T. Daniel, et al., "Induction of G0/G1 cell cycle arrest in ovarian carcinoma cells by the antiinflammatory drug NS-398, but not by COX-2-specific RNA interference," Oncogene, vol. 22, no. 54, pp. 8653-8661, 2003.

[33] G. S. Charames and B. Bapat, "Cyclooxygenase-2 knockdown by RNA interference in colon cancer," International Journal of Oncology, vol. 28, no. 2, pp. 543-549, 2006.

[34] S.-I. Kobayashi, M. Sakatani, S. Kobayashi, K. Okuda, and M. Takahashi, "Gene silencing of cyclooxygenase- 2 mRNA by RNA interference in bovine cumulus-granulosa cells," Journal of Reproduction and Development, vol. 53, no. 6, pp. 1305$1311,2007$.

[35] P. T. Bozza, J. L. Payne, S. G. Morham, R. Langenbach, O. Smithies, and P. F. Weller, "Leukocyte lipid body formation and eicosanoid generation: cyclooxygenase-independent inhibition by aspirin," Proceedings of the National Academy of Sciences of the United States of America, vol. 93, no. 20, pp. 11091-11096, 1996.

[36] M. Grilli, M. Pizzi, M. Memo, and P. Spano, "Neuroprotection by aspirin and sodium salicylate through blockade of NFkappaB activation," Science, vol. 274, no. 5291, pp. 1383-1385, 1996.

[37] D. J. E. Elder, D. E. Halton, A. Hague, and C. Paraskeva, "Induction of apoptotic cell death in human colorectal carcinoma cell lines by a cyclooxygenase-2 (COX-2)-selective nonsteroidal anti-inflammatory drug: independence from COX-2 protein expression," Clinical Cancer Research, vol. 3, no. 10, pp. 1679-1683, 1997.

[38] J. T. E. Lim, G. A. Piazza, E. K.-H. Han, et al., "Sulindac derivatives inhibit growth and induce apoptosis in human prostate cancer cell lines," Biochemical Pharmacology, vol. 58, no. 7, pp. 1097-1107, 1999.

[39] A. Strillacci, C. Griffoni, E. Spisni, M. C. Manara, and V. Tomasi, "RNA interference as a key to knockdown overexpressed cyclooxygenase-2 gene in tumour cells," British Journal of Cancer, vol. 94, no. 9, pp. 1300-1310, 2006.

[40] R. Wang, X. Wang, F. Lin, P. Gao, K. Dong, and H.-Z. Zhang, "shRNA-targeted cyclooxygenase (COX)-2 inhibits proliferation, reduces invasion and enhances chemosensitivity in laryngeal carcinoma cells," Molecular and Cellular Biochemistry, vol. 317, no. 1-2, pp. 179-188, 2008.

[41] P. Sansone, G. Piazzi, P. Paterini, et al., "Cyclooxygenase2/carbonic anhydrase-IX up-regulation promotes invasive potential and hypoxia survival in colorectal cancer cells," Journal of Cellular and Molecular Medicine, vol. 13, no. 9b, pp. 3876-3887, 2009.

[42] L. Timmons and A. Fire, "Specific interference by ingested dsRNA," Nature, vol. 395, no. 6705, p. 854, 1998.

[43] R. C. May and R. H. A. Plasterk, "RNA interference spreading in C. elegans," Methods in Enzymology, vol. 392, pp. 308-315, 2005.
[44] S. Xiang, J. Fruehauf, and C. J. Li, "Short hairpin RNAexpressing bacteria elicit RNA interference in mammals," Nature Biotechnology, vol. 24, no. 6, pp. 697-702, 2006.

[45] A. C. Keetes, J. H. Fruehauf, S. Xiang, P. D. Parker, and C. J. $\mathrm{Li}$, "Cequent pharmaceuticals, Inc.: the biological pitcher for RNAi therapeutics," Pharmacogenomics, vol. 8, no. 7, pp. 867871, 2007.

[46] N. Rajewsky, "microRNA target predictions in animals," Nature Genetics, vol. 38, no. 1, pp. S8-S13, 2006.

[47] S. Griffiths-Jones, H. K. Saini, S. van Dongen, and A. J. Enright, "miRBase: tools for microRNA genomics," Nucleic Acids Research, vol. 36, no. 1, pp. D154-D158, 2008.

[48] Y. Lee, C. Ahn, J. Han, et al., "The nuclear RNase III Drosha initiates microRNA processing," Nature, vol. 425, no. 6956, pp. 415-419, 2003.

[49] G. Hutvágner, J. McLachlan, A. E. Pasquinelli, E. Bálint, T. Tuschl, and P. D. Zamore, "A cellular function for the RNAinterference enzyme dicer in the maturation of the let-7 small temporal RNA,” Science, vol. 293, no. 5531, pp. 834-838, 2001.

[50] D. P. Bartel, "MicroRNAs: genomics, biogenesis, mechanism, and function," Cell, vol. 116, no. 2, pp. 281-297, 2004.

[51] J. Lu, G. Getz, E. A. Miska, et al., "MicroRNA expression profiles classify human cancers," Nature, vol. 435, no. 7043, pp. 834-838, 2005.

[52] A. J. Schetter, S. Y. Leung, J. J. Sohn, et al., "MicroRNA expression profiles associated with prognosis and therapeutic outcome in colon adenocarcinoma," Journal of the American Medical Association, vol. 299, no. 4, pp. 425-436, 2008.

[53] W. C. S. Cho, "OncomiRs: the discovery and progress of microRNAs in cancers," Molecular Cancer, vol. 6, article 60, 2007.

[54] A. L. Gartel and E. S. Kandel, "miRNAs: little known mediators of oncogenesis," Seminars in Cancer Biology, vol. 18, no. 2, pp. 103-110, 2008.

[55] Y. Akao, Y. Nakagawa, and T. Naoe, "MicroRNAs 143 and 145 are possible common onco-microRNAs in human cancers," Oncology Reports, vol. 16, no. 4, pp. 845-850, 2006.

[56] D. A. Dixon, N. D. Tolley, P. H. King, et al., "Altered expression of the mRNA stability factor HuR promotes cyclooxygenase-2 expression in colon cancer cells," Journal of Clinical Investigation, vol. 108, no. 11, pp. 1657-1665, 2001.

[57] A. Chakrabarty, S. Tranguch, T. Daikoku, K. Jensen, H. Furneaux, and S. K. Dey, "MicroRNA regulation of cyclooxygenase-2 during embryo implantation," Proceedings of the National Academy of Sciences of the United States of America, vol. 104, no. 38, pp. 15144-15149, 2007.

[58] T. Daikoku, Y. Hirota, S. Tranguch, et al., "Conditional loss of uterine Pten unfailingly and rapidly induces endometrial cancer in mice," Cancer Research, vol. 68, no. 14, pp. 5619$5627,2008$.

[59] A. Strillacci, C. Griffoni, P. Sansone, et al., "MiR-101 downregulation is involved in cyclooxygenase-2 overexpression in human colon cancer cells," Experimental Cell Research, vol. 315, no. 8, pp. 1439-1447, 2009.

[60] N. Shanmugam, M. A. Reddy, and R. Natarajan, "Distinct roles of heterogeneous nuclear ribonuclear protein $\mathrm{K}$ and microRNA-16 in cyclooxygenase-2 RNA stability induced by S100b, a ligand of the receptor for advanced glycation end products," Journal of Biological Chemistry, vol. 283, no. 52, pp. 36221-36233, 2008.

[61] K. Yamamoto, T. Arakawa, N. Ueda, and S. Yamamoto, "Transcriptional roles of nuclear factor kappa B and nuclear factor-interleukin-6 in the tumour necrosis factor alphadependent induction of cyclooxygenase-2 in MC3T3-E1 cells," 
Journal of Biological Chemistry, vol. 270, no. 52, pp. 3131531320, 1995.

[62] K. K. Wu, J.-Y. Liou, and K. Cieslik, "Transcriptional Control of COX-2 via C/EBPbeta," Arteriosclerosis, Thrombosis, and Vascular Biology, vol. 25, no. 4, pp. 679-685, 2005.

[63] J.-C. Chen, K.-C. Huang, B. Wingerd, W.-T. Wu, and W.W. Lin, "HMG-CoA reductase inhibitors induce COX-2 gene expression in murine macrophages: role of MAPK cascades and promoter elements for CREB and C/EBP $\beta$," Experimental Cell Research, vol. 301, no. 2, pp. 305-319, 2004.

[64] J. Duque, M. Fresno, and M. A. Iñiguez, "Expression and function of the nuclear factor of activated $\mathrm{T}$ cells in colon carcinoma cells: involvement in the regulation of cyclooxygenase2," Journal of Biological Chemistry, vol. 280, no. 10, pp. 8686$8693,2005$.

[65] R. Grau, M. A. Iñiguez, and M. Fresno, "Inhibition of activator protein 1 activation, vascular endothelial growth factor, and cyclooxygenase- 2 expression by 15-deoxy-delta12,14prostaglandin $\mathrm{J} 2$ in colon carcinoma cells: evidence for a redox-sensitive peroxisome proliferator-activated receptorgamma-independent mechanism," Cancer Research, vol. 64, no. 15 , pp. 5162-5171, 2004.

[66] H. Ikawa, H. Kameda, H. Kamitani, et al., "Effect of PPAR activators on cytokine-stimulated cyclooxygenase-2 expression in human colorectal carcinoma cells," Experimental Cell Research, vol. 267, no. 1, pp. 73-80, 2001.

[67] A. Kaidi, D. Qualtrough, A. C. Williams, and C. Paraskeva, "Direct transcriptional up-regulation of cyclooxygenase-2 by hypoxia-inducible factor (HIF)-1 promotes colorectal tumor cell survival and enhances HIF-1 transcriptional activity during hypoxia," Cancer Research, vol. 66, no. 13, pp. 66836691, 2006.

[68] H. Inoue, C. Yokoyama, S. Hara, Y. Tone, and T. Tanabe, "Transcriptional regulation of human prostaglandinendoperoxide synthase- 2 gene by lipopolysaccharide and phorbol ester in vascular endothelial cells. Involvement of both nuclear factor for interleukin-6 expression site and cAMP response element," Journal of Biological Chemistry, vol. 270, no. 42, pp. 24965-24971, 1995.

[69] B. Thomas, F. Berenbaum, L. Humbert, et al., "Critical role of C/EBPdelta and C/EBPbeta factors in the stimulation of the cyclooxygenase- 2 gene transcription by interleukin-1beta in articular chondrocytes," European Journal of Biochemistry, vol. 267, no. 23, pp. 6798-6809, 2000.

[70] Y. Kim and S. M. Fischer, "Transcriptional regulation of cyclooxygenase-2 in mouse skin carcinoma cells: regulatory role of CCAAT/enhancer-binding proteins in the differential expression of cyclooxygenase-2 in normal and neoplastic tissues," Journal of Biological Chemistry, vol. 273, no. 42, pp. 27686-27694, 1998.

[71] J. Shao, H. Sheng, H. Inoue, J. D. Morrow, and R. N. DuBois, "Regulation of constitutive cyclooxygenase-2 expression in colon carcinoma cells," Journal of Biological Chemistry, vol. 275, no. 43, pp. 33951-33956, 2000.

[72] M. A. Saunders, L. Sansores-Garcia, D. W. Gilroy, and K. $\mathrm{K}$. Wu, "Selective suppression of CCAAT/enhancer-binding protein beta binding and cyclooxygenase-2 promoter activity by sodium salicylate in quiescent human fibroblasts," Journal of Biological Chemistry, vol. 276, no. 22, pp. 18897-18904, 2001.

[73] J. Xing, D. D. Ginty, and M. E. Greenberg, "Coupling of the RAS-MAPK pathway to gene activation by RSK2, a growth factor-regulated CREB kinase," Science, vol. 273, no. 5277, pp. 959-963, 1996.
[74] J. Soutschek, A. Akinc, B. Bramlage, et al., "Therapeutic silencing of an endogenous gene by systemic administration of modified siRNAs," Nature, vol. 432, no. 7014, pp. 173-178, 2004.

[75] M. Thomas, J. J. Lu, Q. Ge, et al., "Full deacylation of polyethylenimine dramatically boosts its gene delivery efficiency and specificity to mouse lung," Proceedings of the National Academy of Sciences of the United States of America, vol. 102, pp. 5679-5684, 2005.

[76] S. H. Kim, J. H. Jeong, S. H. Lee, S. W. Kim, and T. G. Park, "PEG conjugated VEGF siRNA for anti-angiogenic gene therapy," Journal of Controlled Release, vol. 116, no. 2, pp. 123129, 2006.

[77] M. Mikhaylova, I. Stasinopoulos, Y. Kato, D. Artemov, and Z. M. Bhujwalla, "Imaging of cationic multifunctional liposomemediated delivery of COX-2 siRNA," Cancer Gene Therapy, vol. 16, no. 3, pp. 217-226, 2009.

[78] H. Hatakeyama, E. Ito, H. Akita, et al., "A pH-sensitive fusogenic peptide facilitates endosomal escape and greatly enhances the gene silencing of siRNA-containing nanoparticles in vitro and in vivo," Journal of Controlled Release, vol. 139, no. 2, pp. 127-132, 2009.

[79] F. J.-J. Toublan, S. Boppart, and K. S. Suslick, "Tumor targeting by surface-modified protein microspheres," Journal of the American Chemical Society, vol. 128, no. 11, pp. 3472-3473, 2006.

[80] Y. Zeng, R. Yi, and B. R. Cullen, "MicroRNAs and small interfering RNAs can inhibit mRNA expression by similar mechanisms," Proceedings of the National Academy of Sciences of the United States of America, vol. 100, no. 17, pp. 9779-9784, 2003.

[81] A. L. Jackson, S. R. Bartz, J. Schelter, et al., "Expression profiling reveals off-target gene regulation by RNAi," Nature Biotechnology, vol. 21, no. 6, pp. 635-637, 2003.

[82] Y. Lee, R. C. Samaco, J. R. Gatchel, C. Thaller, H. T. Orr, and H. Y. Zoghbi, "miR-19, miR-101 and miR-130 co-regulate ATXN1 levels to potentially modulate SCA1 pathogenesis," Nature Neuroscience, vol. 11, no. 10, pp. 1137-1139, 2008.

[83] J. M. Friedman, G. Liang, C.-C. Liu, et al., "The putative tumor suppressor microRNA-101 modulates the cancer epigenome by repressing the polycomb group protein EZH2," Cancer Research, vol. 69, no. 6, pp. 2623-2629, 2009.

[84] S. Kim, J. L. Ui, N. K. Mi, et al., "MicroRNA miR-199a* regulates the MET proto-oncogene and the downstream extracellular signal-regulated kinase 2 (ERK2)," Journal of Biological Chemistry, vol. 283, no. 26, pp. 18158-18166, 2008.

[85] R. Chen, A. B. Alvero, D. A. Silasi, et al., "Regulation of IKKbeta by miR-199a affects NF-kappaB activity in ovarian cancer cells," Oncogene, vol. 27, no. 34, pp. 4712-4723, 2008.

[86] E. Hiroki, J.-I Akahira, F. Suzuki, et al., "Changes in microRNA expression levels correlate with clinicopathological features and prognoses in endometrial serous adenocarcinomas," Cancer Science, vol. 101, no. 1, pp. 241-249, 2010.

[87] R. L. Boudreau, A. M. Monteys, and B. L. Davidson, "Minimizing variables among hairpin-based RNAi vectors reveals the potency of shRNAs," RNA, vol. 14, no. 9, pp. 1834-1844, 2008.

[88] D. Grimm, K. L. Streetz, C. L. Jopling, et al., "Fatality in mice due to oversaturation of cellular microRNA/short hairpin RNA pathways," Nature, vol. 441, no. 7092, pp. 537-541, 2006.

[89] A. J. Bridge, S. Pebernard, A. Ducraux, A.-L. Nicoulaz, and R. Iggo, "Induction of an interferon response by RNAi vectors in mammalian cells," Nature Genetics, vol. 34, no. 3, pp. 263-264, 2003. 
[90] A. D. Judge, V. Sood, J. R. Shaw, D. Fang, K. McClintock, and I. MacLachlan, "Sequence-dependent stimulation of the mammalian innate immune response by synthetic siRNA," Nature Biotechnology, vol. 23, no. 4, pp. 457-462, 2005. 


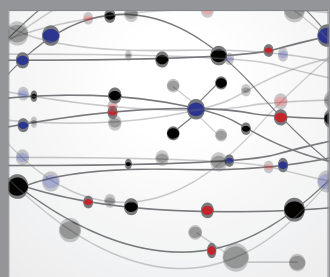

The Scientific World Journal
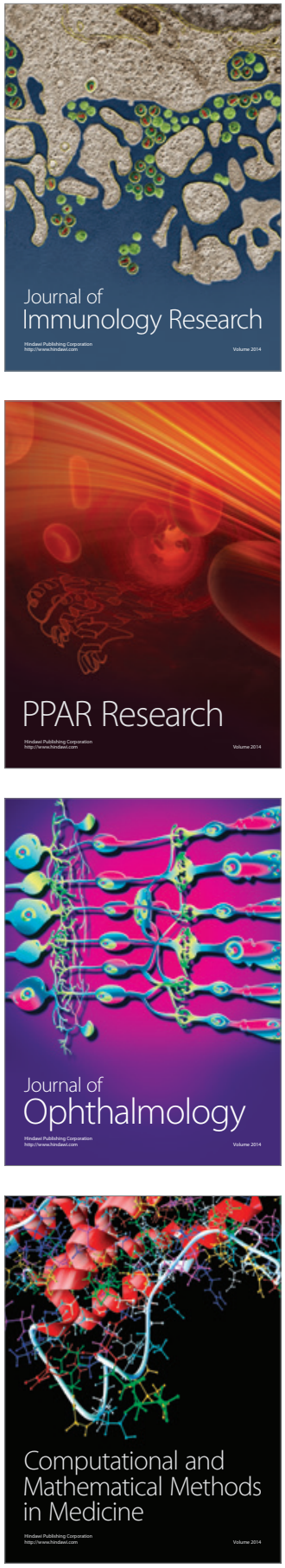

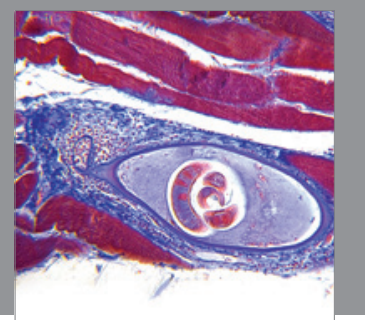

Gastroenterology

Research and Practice
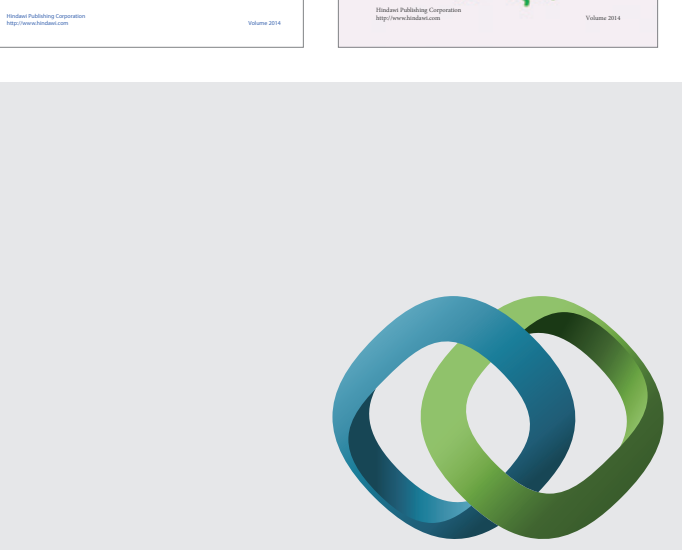

\section{Hindawi}

Submit your manuscripts at

http://www.hindawi.com
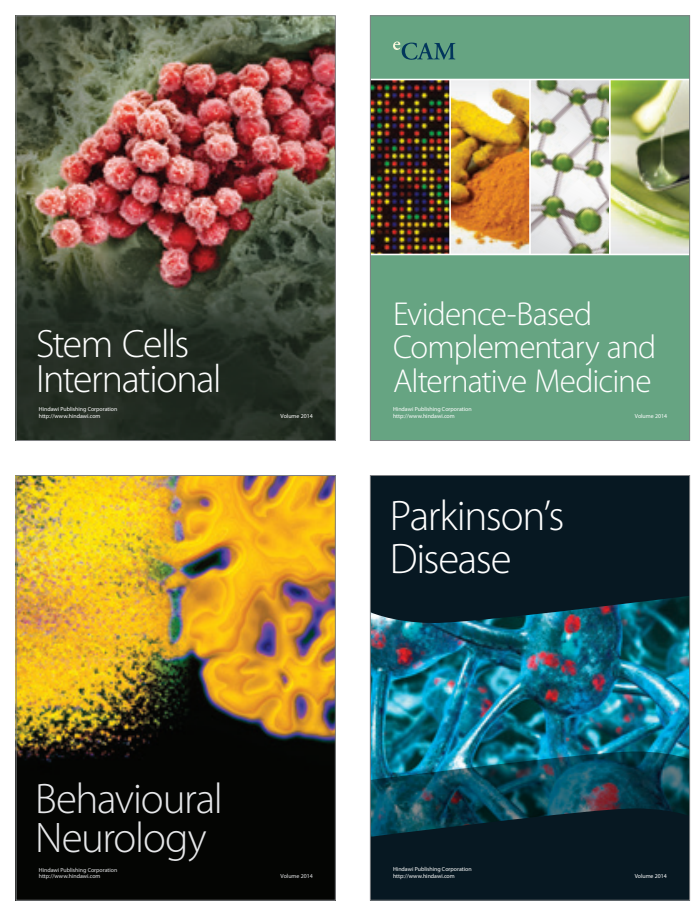

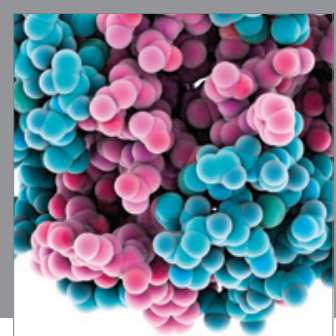

Journal of
Diabetes Research

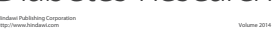

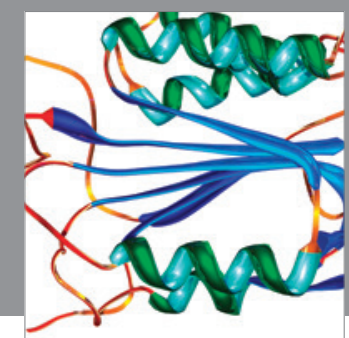

Disease Markers
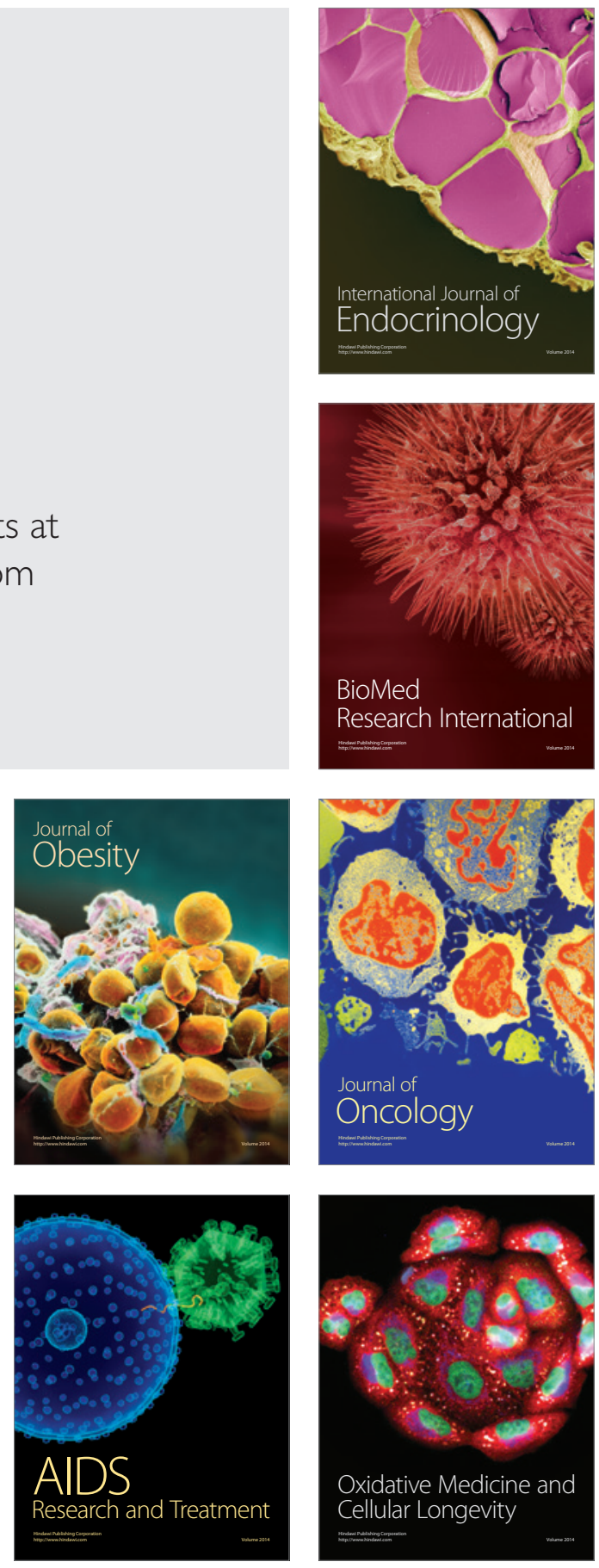